\title{
Economic Analysis of Water Treatments for Phosphorus Removal in Florida 1
}

Daisuke Sano, Alan Hodges, and Robert Degner ${ }^{2}$

\section{Abstract}

Excessive phosphorus loads in urban and agricultural runoff are identified as one of the greatest threats to the natural environment of Central and South Florida. This study compares the cost effectiveness of two different water treatment systems that have demonstrated an enhanced phosphorus removal ability utilizing aquatic plants and biomass: Wetland Stormwater Treatment Areas (STA) and Managed Aquatic Plant Systems (MAPS). Cost effectiveness, expressed as dollars per kilogram $(\mathrm{kg})$ of phosphorus removed, is calculated from the net present value cost for capital, operation and management, including residue management, and benefits from water storage/supply and recreational use, divided by the projected total phosphorus removal over fifty years. MAPS demonstrated the lowest cost at $\$ 24$ per $\mathrm{kg}$ for systems designed to treat waters with $300 \mathrm{ppb}$ (parts per billion) phosphorus to a level of $155 \mathrm{ppb}$. Reservoir-Assisted STA, which treated $540 \mathrm{ppb}$ to $40 \mathrm{ppb}$ phosphorus concentration in Central Florida, had an estimated cost of \$77. STAs starting with concentrations ranging from 40 to
$180 \mathrm{ppb}$ and facing a target of $10 \mathrm{ppb}$ phosphorus concentration in South Florida had much higher cost estimates, ranging between $\$ 268$ and $\$ 1,346$ per $\mathrm{kg}$.

\section{Introduction}

Restoration of the Everglades ecosystem is of great interest to Florida, the nation, and the international community. Over 9,000 square kilometers, or 3,474 square miles, of the remaining wetlands are included in the Everglades Protection Area (EPA). Phosphorus has been identified as the nutrient most responsible for changing the environment in the Everglades by causing excessive growth of undesirable vegetation. Historically, the major source of nutrient loading of phosphorus to the Everglades had been atmospheric precipitation. More recently, canal discharges originating primarily as agricultural runoff reportedly have altered water quality in several areas within the marsh and, in particular, increased phosphorus loading has been associated with numerous changes in ecological characteristics. Thus, reducing phosphorus loading to the EPA is central to restoring and preserving the Everglades. To achieve the long-term water quality

\footnotetext{
1. This is EDIS document FE576, a publication of the Department of Food and Resource Economics, Florida Cooperative Extension Service, Institute of Food and Agricultural Sciences, University of Florida, Gainesville, FL. Published November 2005. Please visit the EDIS website at http://edis.ifas.ufl.edu.

This is an excerpt of "Economic Analysis of Water Treatments for Phosphorus Removal in Florida," Food and Resource Economics Department, University of Florida, 2004.

2. Daisuke Sano, former Post-Doctoral Associate, Alan Hodges, Associate-In, and Robert Degner, Professor, Department of Food and Resource Economics, Florida Cooperative Extension Service, Institute of Food and Agricultural Sciences, University of Florida, Gainesville, FL.
} 
goals, the State of Florida enacted the Everglades Forever Act in 1994. The phosphorus limit for water entering the EPA was proposed at $10 \mathrm{ppb}$ (parts per billion) by the Florida Department of Environmental Protection and approved by the Environmental Regulation Commission in July 2003. To secure the water quality in Lake Okeechobee, the central part of a large interconnected aquatic ecosystem in South Florida that provides a number of values to society and nature, including water supply for agriculture and urban areas, the State of Florida enacted the Lake Okeechobee Protection Act in 2002, mandating a total maximum daily load, which results in 140 metric tons per year of phosphorus to achieve the targeted $40 \mathrm{ppb}$ in-lake phosphorus concentration. In the same year, to give a framework and guide to various efforts of restoring, protecting, and preserving the water resources of central and south Florida, the Comprehensive Everglades Restoration Plan was authorized under the Water Resources Development Act of 2000 to embrace a wider range of environmental management such as flood protection and agricultural/urban water supplies.

Best Management Practices (BMP) is one of a variety of phosphorus reduction efforts for agricultural producers. STAs, large constructed wetlands that reduce the downstream phosphorus load by retaining phosphorus in the soils and biomass, have been constructed or planned as a means for reducing non-point phosphorus loads.

Four of the six STAs in the Everglades Construction Project (ECP) Basins, which are designed to treat waters flowing from the Everglades Agricultural Area, are fully operational (Figure 1). Three of these four STAs partially employ Submerged Aquatic Vegetation (SAV) technology, which enhances phosphorus uptake by managing submerged aquatic vegetation, as opposed to ordinary STAs, which rely primarily on emergent macrophytes to remove phosphorus from waters. The South Florida Water Management District (SFWMD) identified SAV as an effective way to enhance phosphorus reduction.

The Managed Aquatic Plant System (MAPS), an aquatic plant-based water treatment system developed by HydroMentia, Inc., has been selected as one of the thirty-two projects conducted in the Lake Okeechobee Watershed (LOW). The facility involves the cultivation of a mixed community of periphytic algae, cultured on an engineered geomembrane, overlain with an attachment grid upon which treatment waters are discharged (the system is called Algal Turf Scrubber, or ATS ${ }^{\mathrm{TM}}$ ). Algae is scraped from the membrane and collected with an automatic rake at a harvesting station. The harvested biomass is then conveyed to a bunker for storage and further processing. One feature that distinguishes MAPS from STAs is that plant biomass is periodically harvested and recycled into potentially marketable products. Another notable feature of the MAPS water treatment is that it requires relatively little land, enabling a MAPS treatment facility to be geographically compact.

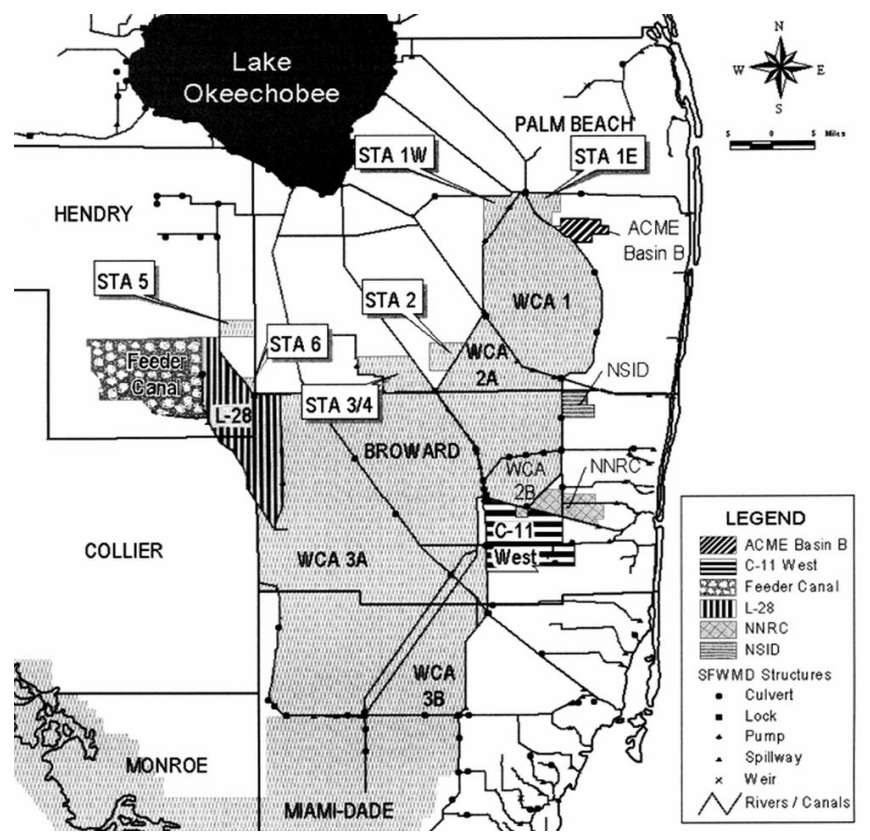

Figure 1. Locations of stormwater treatment areas in Everglades construction project and Everglades stormwater program basins (Source: Brown \& Caldwell, 2002).

\section{Analytical Approach and Methods}

\section{Compared Water Treatment System Projects}

The basic characteristics of water treatment system compared in this study are summarized in Table 1: six STAs located in the Everglades Construction Project (ECP) Basins, three STAs planned in the Everglades Stormwater Program (ESP) Basins, one Reservoir-Assisted Stormwater 
Treatment Area (RASTA) planned in the Lake Okeechobee Watershed (LOW), and MAPS designed to treat waters with $300 \mathrm{ppb}$ phosphorus. In order to compare the STAs with MAPS, only the STAs employing biological technologies adopted or recommended in the Long-Term Plan for Achieving Water Quality Goals (“Long-Term Plan"), which was approved by the South Florida Water Management District (SFWMD), were chosen. RASTA not enhanced with biological technology is included in this study because RASTA faces the same phosphorus removal target and similar phosphorus loading conditions as MAPS. All data used in this study were previously prepared by environmental firms and submitted to SFWMD (as noted as sources in Table 1) and, unless mentioned, they were preserved as they were found in the cited documents throughout the study.

\section{Cost Effectiveness Analysis}

In order to compare cost effectiveness among facilities, costs were estimated as cost per $\mathrm{kg}$ of phosphorus removed, calculated from total net costs divided by the projected total fifty-year phosphorus removal. Net present value costs (discounted terms) were the sum of costs, including capital costs, operation and management (O\&M) costs, replacement costs, and benefits (water benefits and recreation benefits) that have opposite signs to costs, over fifty years. The associated contingency costs and project management costs were included in either capital costs or O\&M costs. All monetary values were expressed in 2003 dollars, with a composite discount rate (inflation-adjusted discount rate) of 3.375 percent.

In addition to costs in cited reports, costs associated with residue management were also taken into consideration. The recent studies found that the sediments in STAs/ RASTA, the essential medium that absorbs and retains phosphorus, could no longer retain phosphorus at some indeterminate point or may release phosphorus under unfavorable conditions; thus proper management of the sediments becomes necessary. In this study, it is assumed that the residue is removed in the twenty-fifth year of the STA and RASTA operations. The cost was calculated by using a unit acreage cost of residue removal $(\$ 3,213$ per acre) reported by DB Environmental in 2003, multiplied by the acreages of water treatment facilities. In the case of MAPS, residue is excavated every year. The cost was calculated by using a unit volume cost of residue removal ( $\$ 60$ per ton of sediment) multiplied by the projected volume of the annual residue removed from the treatment facility. In both cases, it is assumed that the unit volume cost remains constant over the fifty-year forecasting period.

To account for the socio-economic benefits from water treatment facilities, two benefits were considered: water storage/supply benefits and recreation benefits. Given the rapid population growth in South Florida, water treatment facilities will play an important role by increasing water supplies to lessen possible water shortages. The projects' enhanced water supplies and the price of water based upon a survey of people's willingness-to-pay during water shortage events were utilized to calculate each facility's share of contributing such water storage/supply benefits. The imputed unit price of water was $\$ 13.21$ per 1,000 gallons calculated from data in the Integrated Feasibility Report and Programmatic Environmental Impact Statement reported by United States Army Corps of Engineers in 1999.

Recreation benefits are based on the assumption that water treatment facilities provide residents in the region or visitors to the region with benefits such as hunting and wildlife watching. STA-5 and STA-1W have been offering the general public waterfowl hunting opportunities since the 2002/2003 season as well as bird watching trips since the 2004/2005 season. The estimated unit recreational benefits per acre of STA were $\$ 11.80$, using the average expenditure per hunter-day calculated from the 2001 National Survey of Fishing, Hunting, and Wildlife-Associated Recreation, Florida and actual number of the visitors observed in STA-5 and STA-1W during the 2004/2005 season. This estimate only includes expenditures related to equipment and trips and thus captures the direct economic effects on the local economy from hunting. The multiplier effects were ignored in this study due to lack of estimates. 


\section{Results and Discussion}

\section{Costs and Benefits of Stormwater Treatment Areas in the Everglades Construction Project Basins (Treatments 1 through 6)}

Total costs ranged from $\$ 56$ million to $\$ 352$ million (Table 2). Capital costs represented forty-seven to sixty percent of total costs except for STA-1E (Treatment 1).

Total non-phosphorus-removal benefits ranged from $\$ 7$ million to $\$ 50$ million (Table 2). The ratio of these benefits to total costs varied from ten to fourteen percent among STAs, averaging twelve percent. This result illustrates that benefits from water storage/supply as well as recreation could significantly reduce net costs during the operation period.

Fifty-year net present value costs ranged from $\$ 50$ million to $\$ 302$ million (Table 2). Costs per kg of phosphorus removed ranged from $\$ 369$ to $\$ 1,346$. Higher cost per $\mathrm{kg}$ of phosphorus removed implied lower phosphorus removal capacity per acre among STAs in ECP Basins (Treatments 1 through 6). The average cost per $\mathrm{kg}$ of phosphorus removed becomes slightly larger when it is weighted with treatment areas. This means that the larger the treatment area, the higher the cost becomes among these STAs (Treatment 1 through 6). This result does not support the existence of economies of scale.

\section{Costs and Benefits of Stormwater Treatment Areas in the Everglades Stormwater Program Basins (Treatments 7 through 9)}

Total costs ranged from $\$ 28$ million to $\$ 112$ million (Table 2). Capital costs represent seventy-eight percent of total costs on average. Shares of O\&M costs occupied in total cost were smaller relative to those observed in STAs in ECP Basins (Treatments 1 through 6), with an average of eighteen percent.

Total non-phosphorus-removal benefits ranged from $\$ 1$ million to $\$ 8$ million. The ratio of these benefits to total cost varied from four to eight percent, averaging seven percent (Table 2).
Fifty-year net present value cost ranged from $\$ 27$ million to \$104 million. Costs per $\mathrm{kg}$ of phosphorus removed resulted in a range between \$268 and \$686 (Table 2). These results are similar to those of STAs in ECP Basins (Treatments 1 through $6)$.

\section{Costs and Benefits of Reservoir-Assisted Stormwater Treatment Areas in the Lake Okeechobee Watershed Project Basins (Treatment 11)}

Total costs were estimated at \$244 million (Table 2). Capital costs represented approximately fifty-eight percent of total cost. This was similar to the average results for ECP Basins (Treatments 1 through 6). O\&M costs were thirty-nine percent of total costs. This falls between those of STAs in ECP Basins (Treatments 1 through 6) and ESP Basins (Treatments 7 through 9).

Total non-phosphorus-removal benefits of RASTA were $\$ 15$ million (Table 2). Water storage/supply benefits were 5.5 percent of total costs and recreation benefits were 0.7 percent. This made the ratio of these benefits to total cost six percent.

Fifty-year net present cost was $\$ 229$ million (Table 2). A significantly larger amount of projected phosphorus removal resulted in a low cost per $\mathrm{kg}$ of phosphorus removed estimated at $\$ 77$, lower than any other STAs in the ECP and ESP Basins (Treatments 1 through 9). Although the fact that STAs (Treatments 1 through 9) and RSTA (Treatment 11) treat waters with different levels of inflow as well as target phosphorus concentrations makes them incomparable (Table 1), this result supports our prior expectation that the cost per kilogram of phosphorus removed would decrease as the phosphorus concentrations in treating waters increase. Consequently, phosphorus removal capacity per acre was higher than any other STAs in the ECP and ESP Basins (Treatments 1 through 9), estimated at $372 \mathrm{~kg}$.

\section{Costs and Benefits of Managed Aquatic Plant Systems (MAPS, Treatment 10)}

Total costs were estimated at $\$ 24.2$ million (Table 2). The most noticeable difference of MAPS (Treatment 10) from RASTA (Treatment 11) is that 
the capital costs had a lower share of total costs at twenty-eight percent. Residue management costs represent considerable portions of total cost (thirty-three percent). Estimated total benefits were relatively small at approximately $\$ 0.13$ million (Table 2).

Fifty-year net present value costs were $\$ 24.1$ million (Table 2). Cost per kg of phosphorus removed was lower than RASTA (Treatment 11) or STAs (Treatments 1 through 9). The MAPS system has a significantly higher phosphorus removal capacity per acre than any other compared systems due to its enhanced phosphorus removal ability of harvesting and removing accumulated biomass. However, it is noted that the simulation of MAPS systems used in this study are not necessarily designed to meet the target phosphorus concentration, and hence result in different levels of load reduction; that is, an efficiency indicator calculated from the removed/improved phosphorus concentration divided by the inflow phosphorus concentration (Table 1). The potential of additional costs for MAPS incurred through improving efficiency to meet target concentrations remains uncertain.

\section{Conclusions and Implications}

Two types of water treatment systems for phosphorus removal in Florida were considered. One type is Stormwater Treatment Areas (STA), which are created wetlands (the more practiced method), and the other type is Managed Aquatic Plant Systems (MAPS), which has been developed and tested at pilot scale in recent years. Both systems utilize biomass for phosphorus removal, including emergent aquatic macrophytes, submerged aquatic vegetation, and periphytic algae. However, there are fundamental differences in the manner of biomass handling and the intensity of phosphorus removal. Specifically, the STA system harvests no biomass while the MAPS system periodically harvests periphytic algae, which is essential for optimum phosphorus removal in the MAPS system. While equipping a facility with harvesting equipment and operations would usually be associated with high capital costs, this is not the case for MAPS. Because of the limited land requirements of MAPS, the share of capital costs in total cost represents only a fraction compared to a typical STA, which requires a large water treatment area at a significant cost. On the other hand, this indicates a relatively higher share of total O\&M costs for MAPS. Because harvesting is an essential part of water treatment with MAPS, requiring management and maintenance throughout the operation period, STAs generally have low maintenance needs. In particular, residue management is a key to the level of maintenance costs for proper operations of MAPS.

In this study, the MAPS system showed a significantly higher phosphorus removal capacity per acre compared to STAs or RASTA. However, this study focused on only economic analysis, particularly cost effectiveness under a set of general and specific assumptions; hence further analyses from other perspectives is needed to provide specific recommendations. 


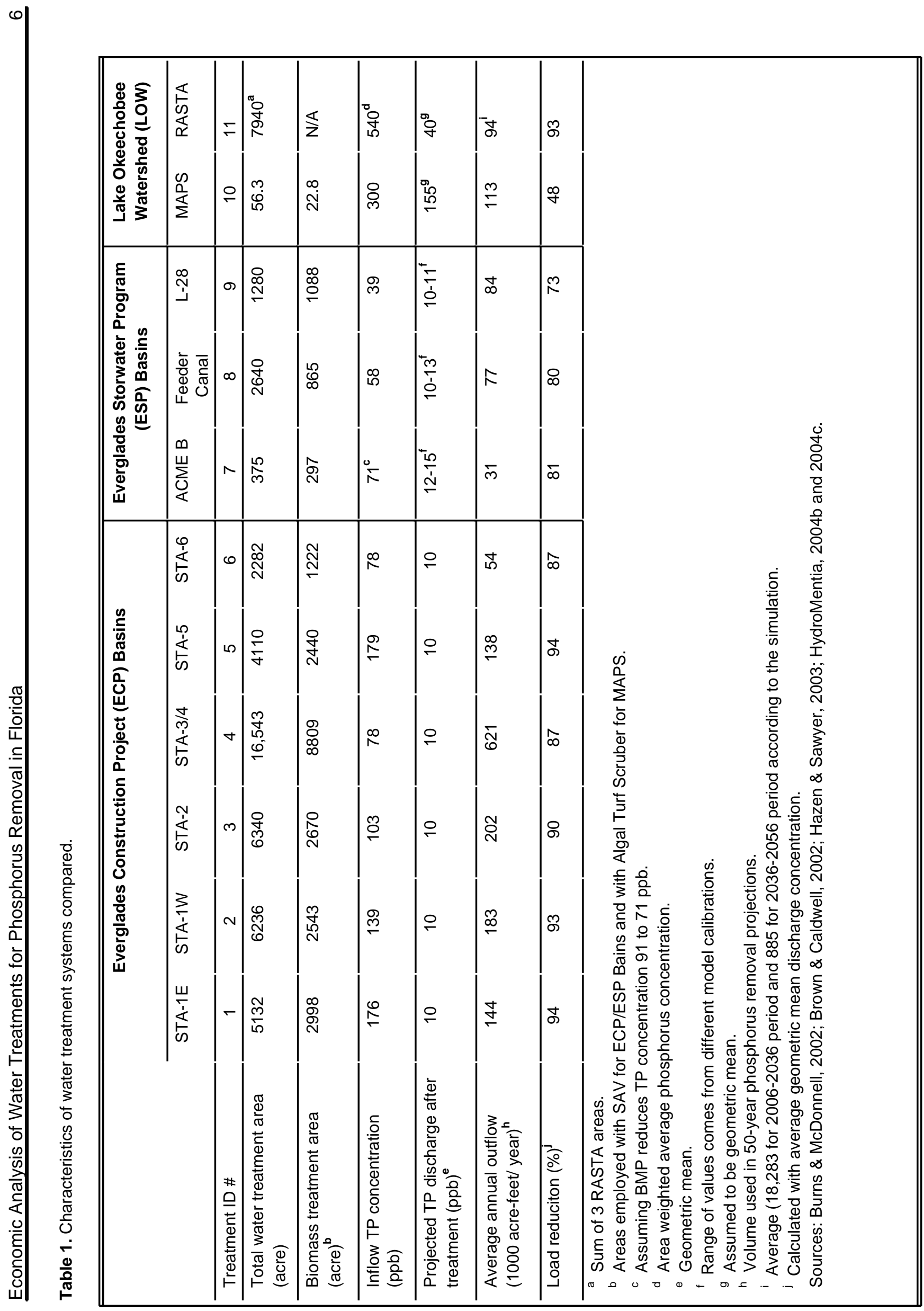




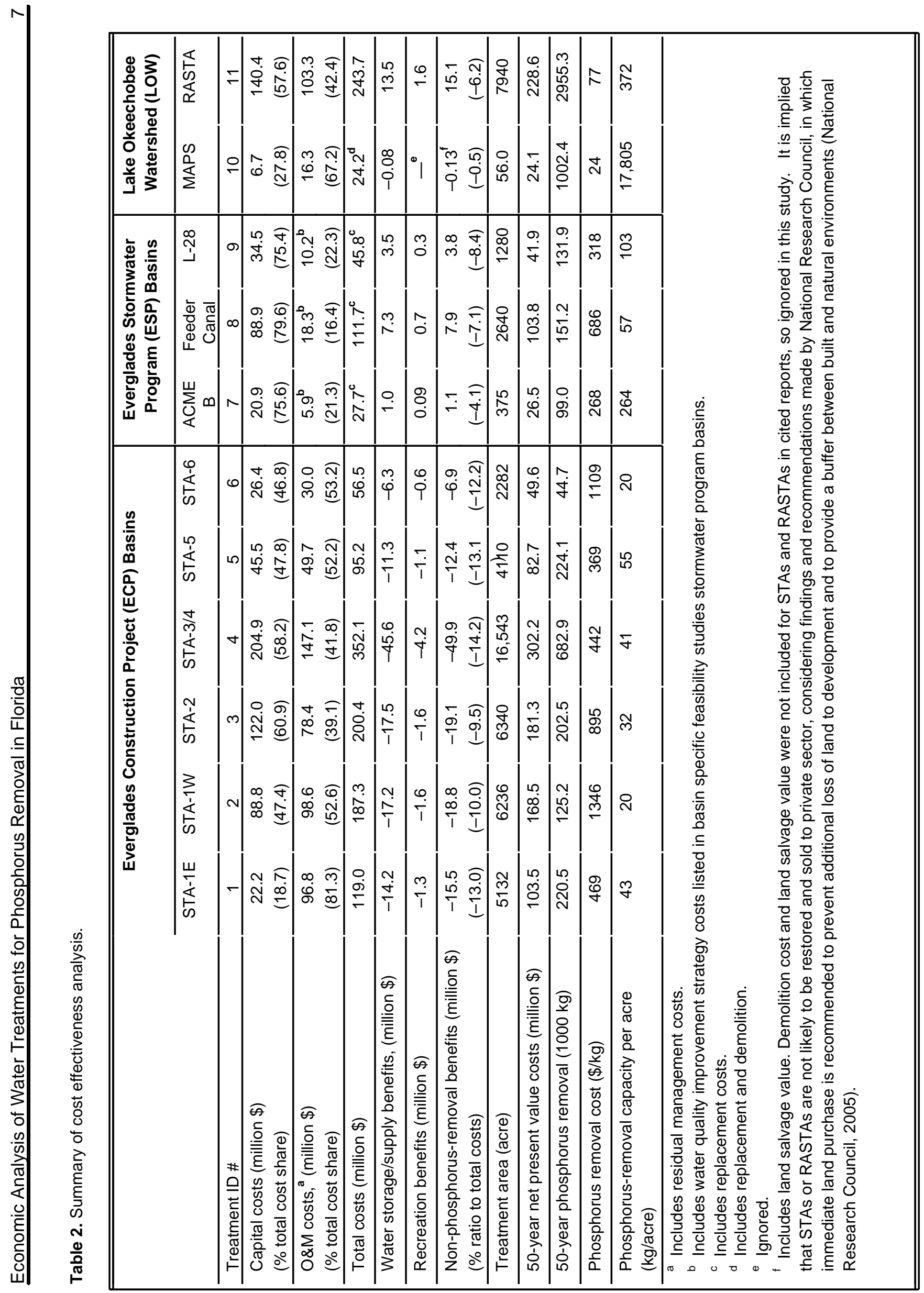

